\title{
Modulation Extension Control for Multilevel Converters Using Triplen Harmonic Injection with Low Switching Frequency
}

\author{
Zhong Du, Leon M. Tolbert, John N. Chiasson \\ Electrical and Computer Engineering \\ The University of Tennessee \\ Knoxville, TN 37996-2100 \\ E-mail: zdu1@utk.edu, tolbert@utk.edu, chiasson@utk.edu
}

\begin{abstract}
This paper presents a modulation extension control method for multilevel converters with low switching frequency. The disadvantage of the fundamental frequency switching control method for multilevel converters is its narrow range of modulation indices where solutions exist. To address this problem, a triplen harmonic compensation method is proposed. First, the resultant method and/or Newton Climbing method are used to find solutions of the switching angles for the fundamental frequency switching scheme control. Second, a triplen harmonic is injected into the multilevel converters accompanied with the fundamental frequency control signals to reduce the required level number of the DC voltages without changing the fundamental component of the phase voltage. The computational results show that the triplen harmonic method indeed reduces the required DC voltage level number to reduce the hardware cost. A 17-level example was implemented with an 11-level $\mathrm{H}$-bridge multilevel converter and an $8 \mu$ s control resolution to demonstrate the triplen harmonic compensation method. The experimental results confirmed the method with this example.
\end{abstract}

Keywords - Multilevel converter; triplen harmonic compensation, modulation extension control.

\section{INTRODUCTION}

The multilevel converter is a promising technology to directly interconnect utility grids with different frequencies, different voltage magnitudes, and different phases. For utility applications, some method must be used to eliminate harmonics to satisfy the total harmonic distortion (THD) requirements as given by IEEE 519 [5].

One control method for multilevel converters is the fundamental frequency switching method $[6,16]$. The benefit of the fundamental frequency switching method is its low switching frequency compared to other switching schemes, such as traditional PWM methods, space vector PWM methods, sub-harmonic PWM methods (SH-PWM) [11], switching frequency optimal PWM (SFO-PWM) [3], and carrier-based PWM methods to help to optimize or balance the switch utilization in multilevel inverters $[12,13]$. To find the switching angles for the fundamental frequency switching method, often numerical methods are utilized, such as Newton's method. However, there are limitations for Newton's method because it requires a good initial guess to solve the transcendental equations characterizing the harmonic content, and Newton's method does not necessarily find all the solutions for the equations.
For this reason, the resultant method was considered in [7] wherein the transcendental equations characterizing the harmonic content are converted into polynomial equations [7]. Elimination theory $[1,2,4,15]$ was then used (along with the special symmetry properties of the equations) to determine the switching angles to eliminate specific harmonics, namely the 5th, 7th, 11th, and 13th. However, as the number of DC sources increases, the degrees of the polynomials in these equations are large, and one reaches the limitations of the capability of contemporary computer algebra software tools (e.g., Mathematica or Maple) to solve the system of polynomial equations using elimination theory with resultants [8].

Another problem related with the fundamental frequency switching control is its narrow modulation index range compared to the traditional PWM control. The third harmonic injection method has been used in both the traditional and multilevel PWM control to increase the output voltage while staying in the linear modulation region $[9,10,13,14]$. To increase the modulation index range while using the fundamental frequency switching control, this paper proposes a modulation extension control method, which is referred to here as the triplen harmonic compensation method.

An experimental 11-level H-bridge multilevel converter is employed to validate the proposed method for the modulation extension control. The experimental results show that the method can effectively eliminate specified harmonics, and the triplen harmonic compensation method can increase the modulation index range and decrease the required DC level number of a multilevel converter resulting in reduced hardware costs.

\section{RESUltANT METHOD FOR FUNDAMENTAL FREQUENCY SWITCHING SCHEME}

An 11-level multilevel converter output voltage waveform with fundamental frequency switching scheme is shown in Fig. 1. The Fourier series expansion of the output voltage waveform shown in Fig. 1 is

$$
\begin{aligned}
V(\omega t)= & \sum_{n=1,3,5 \ldots}^{\infty} \frac{4 V_{d c}}{n \pi}\left(\cos \left(n \theta_{1}\right)+\cos \left(n \theta_{2}\right)\right. \\
& \left.+\cos \left(n \theta_{3}\right)+\cdots+\cos \left(n \theta_{S}\right)\right) \sin (n \omega t)
\end{aligned}
$$

where $s$ is the number of DC sources. Ideally, given a desired fundamental voltage $V_{l}$, one wants to determine the switching angles $\theta_{l}, \cdots, \theta_{s}$ so that $V(\omega t)=V_{l} \sin (\omega t)$, and specific higher 


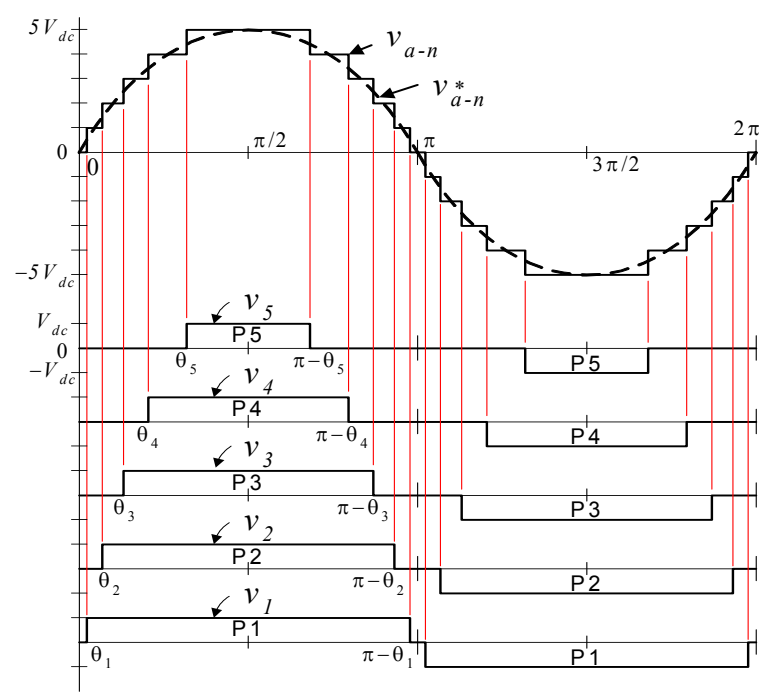

Fig. 1. Output waveform of multilevel converter with fundamental frequency switching scheme.

harmonics of $V(n \omega t)$ are equal to zero. For a three-phase application, the triplen harmonics in each phase need not be cancelled as they automatically cancel in the line-line voltages. For example, in the case of $s=5 \mathrm{DC}$ sources, the 5 th, 7 th, 11 th, 13th order harmonics can cancel. Here the resultant method is employed to find the solutions when they exist.

$$
\begin{aligned}
& \cos \left(\theta_{1}\right)+\cos \left(\theta_{2}\right)+\cos \left(\theta_{3}\right)+\cos \left(\theta_{4}\right)+\cos \left(\theta_{5}\right)=m \\
& \cos \left(5 \theta_{1}\right)+\cos \left(5 \theta_{2}\right)+\cos \left(5 \theta_{3}\right)+\cos \left(5 \theta_{4}\right)+\cos \left(5 \theta_{5}\right)=0 \\
& \cos \left(7 \theta_{1}\right)+\cos \left(7 \theta_{2}\right)+\cos \left(7 \theta_{3}\right)+\cos \left(7 \theta_{4}\right)+\cos \left(7 \theta_{5}\right)=0 \\
& \cos \left(11 \theta_{1}\right)+\cos \left(11 \theta_{2}\right)+\cos \left(11 \theta_{3}\right)+\cos \left(11 \theta_{4}\right)+\cos \left(11 \theta_{5}\right)=0 \\
& \cos \left(13 \theta_{1}\right)+\cos \left(13 \theta_{2}\right)+\cos \left(13 \theta_{3}\right)+\cos \left(13 \theta_{4}\right)+\cos \left(13 \theta_{5}\right)=0
\end{aligned}
$$

The 11-level multilevel converter angle solutions vs. modulation index $m=\pi V_{l} /\left(4 V_{d c}\right)$ are shown in Fig. 2.

\section{Newton Climbing Method for Multilevel CONVERTER}

The fundamental frequency switching angle computation is approached using Newton's method. The initial guess is proposed from the results of lower order transcendental equations by the resultant method or the Newton method. For example, if solutions to the $m$ level case are found by the resultant method [8], these solutions could be used as initial guesses for Newton's method to find solutions to the $m+2$ level case; the solutions to the $m+2$ level case could then be used as initial guesses to find solutions to the $m+4$ level case.

To find as many solutions as possible by Newton's method, as many different initial guesses should be chosen as possible. For this reason, the solutions to the highest-level case found by the resultant method should be used as the first set of initial guesses for Newton's method. By using such a strategy, solutions for higher- level cases can be found step by step. Therefore, the Newton method with such a strategy here is

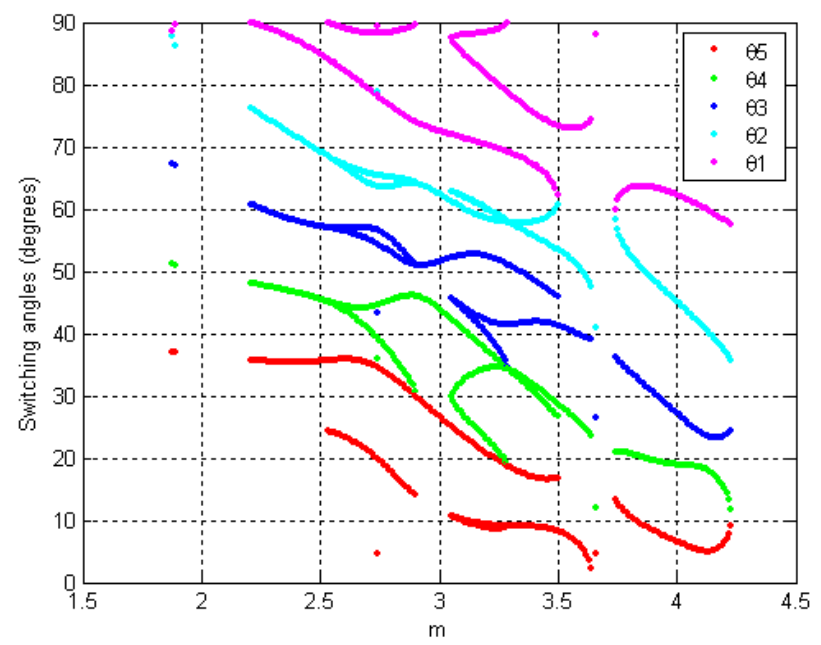

Fig. 2. Switching angle solutions to 11-level case of multilevel converter with fundamental frequency switching scheme.

referred to as Newton Climbing method. Although the Newton Climbing method cannot find all the solutions for the equations, it is still practical for applications because the THD difference for high-order solutions is low for different solution sets. Kato [17] used a similar method by implementing homotopy methods and single-level selective harmonic elimination PWM.

For practical equation solving, $s$ equations require $s$ initial switching angles as initial guesses. The $s-1$ initial switching angles can be used from the previous results of the $s-1$ equations. Only one initial guess is required. In this paper, the first solution search is to use a solution from the low order equations by using the resultant method, plus an initial guess near 90 degrees to find a solution for the higher order equations. If the first solution search is not satisfied, the results of the first search can be used as initial guesses for the second search by shifting the modulation index value in the equations.

The Newton iterative method for the fundamental frequency switching computation is:

$$
x_{n+1}=x_{n}-J^{-1} f
$$

where $x_{n+1}$ is the new value, and $x_{n}$ is the old value. $J$ is the Jacobian matrix for the transcendental equations, and $f$ is the set of transcendental functions.

$$
f=\left[\begin{array}{c}
\sum_{n=1}^{S} \cos \left(h_{1} \theta_{n}\right) \\
\sum_{n=1}^{S} \cos \left(h_{2} \theta_{n}\right) \\
\vdots \\
\sum_{n=1}^{S} \cos \left(h_{S-1} \theta_{n}\right) \\
\sum_{n=1}^{S} \cos \left(h_{s} \theta_{n}\right)
\end{array}\right]
$$

where $h_{i}$ are the odd, non-triplen harmonic numbers. 
The Jacobian matrix is

$J=\left[\begin{array}{ccccc}-h_{1} \sin \left(\theta_{1}\right) & -h_{1} \sin \left(\theta_{2}\right) & \cdots & -h_{1} \sin \left(\theta_{s-1}\right) & -h_{1} \sin \left(\theta_{s}\right) \\ -h_{2} \sin \left(h_{2} \theta_{1}\right) & -h_{2} \sin \left(h_{2} \theta_{2}\right) & \cdots & \vdots & \vdots \\ \vdots & \vdots & & \vdots & \vdots \\ -h_{s-1} \sin \left(h_{s-1} \theta_{1}\right) & & & -h_{s-1} \sin \left(h_{s-1} \theta_{s-1}\right) & -h_{s-1} \sin \left(h_{s-1} \theta_{s}\right) \\ -h_{s} \sin \left(h_{s} \theta_{1}\right) & \cdots & \cdots & -h_{s} \sin \left(h_{s} \theta_{s-1}\right) & -h_{s} \sin \left(h_{s} \theta_{s}\right)\end{array}\right]$

Most of the continuous solutions can be found by the proposed Newton Climbing search method. In this paper, up to the 21-level case has been computed. The 21-level case solutions vs. modulation index $m=\pi V_{I} /\left(4 V_{d c}\right)$ are shown in Fig. 3.

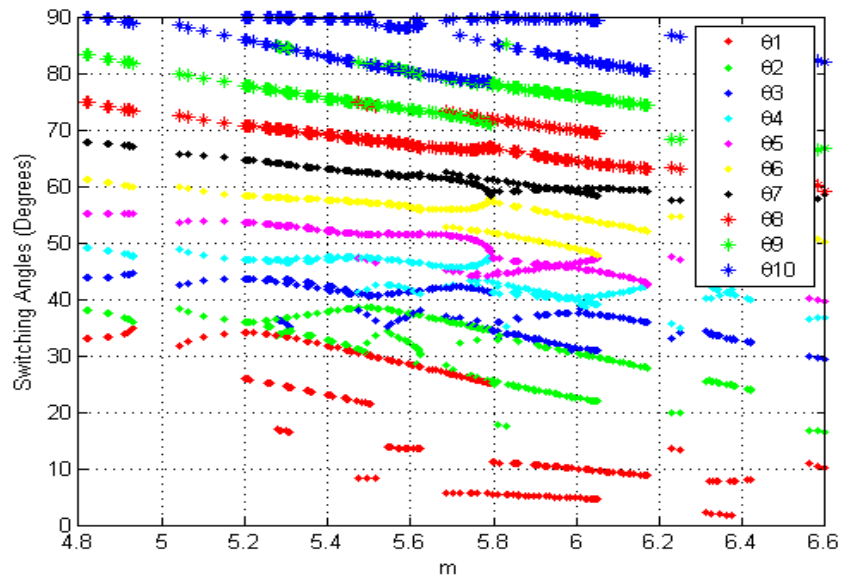

Fig. 3. Solutions to the 21-level case of multilevel converters with fundamental frequency switching scheme.

\section{MOdULATION EXTENSION CONTROL}

A disadvantage of the fundamental frequency switching control is its narrow modulation index region where solutions exist. To extend the linear range of operation for traditional PWM, one method is to add a triplen harmonic. Here, the triplen harmonic compensation method is proposed to increase the modulation index range for the fundamental frequency switching method in multilevel converters.

Assume the switching angles $\theta_{1}, \theta_{2}, \theta_{3}, \theta_{4}, \cdots, \theta_{s}$ are ordered as $\theta_{1} \leq \theta_{2} \leq \theta_{3} \leq \theta_{4} \leq \cdots \leq \theta_{s} \leq \pi / 2$. The working principle is shown in Fig. 4. Before compensation, the original output voltage waveform is shown in the top one, which is a 5level output voltage. The triplen harmonic injected into the converter is shown in the middle waveform of Fig. 4, and the compensated voltage waveform is shown in the bottom waveform, which is a 3-level output voltage. From Fig. 4, it can be seen that to generate the original output voltage, a 5level multilevel converter is necessary. However, after compensation, a 3-level converter can generate the required output voltage waveform. This triplen harmonic voltage does not change the fundamental frequency content, and is cancelled in the line-line voltage.

If the switching angles satisfy the condition

$$
\frac{2 \pi}{3}-\theta_{S} \leq \theta_{S-1},
$$
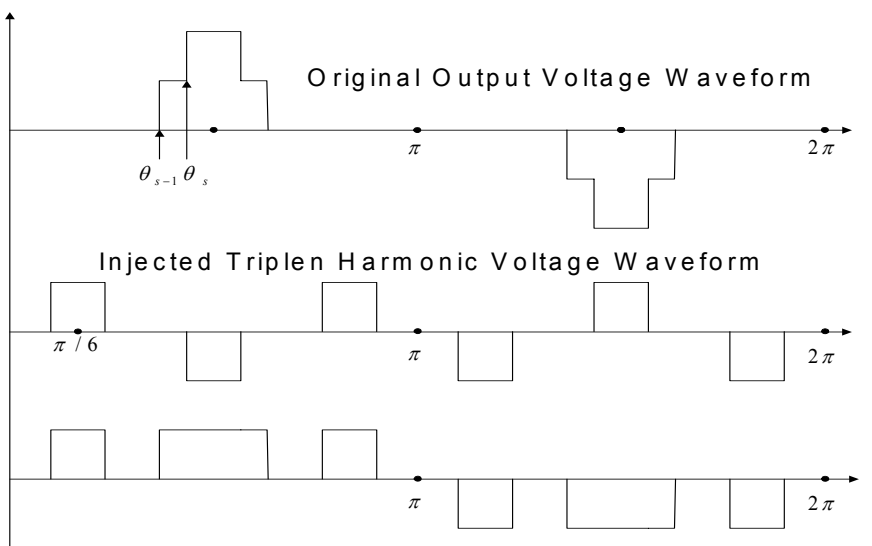

New Output Voltage W aveform

Fig. 4. Triplen harmonic compensation.

then by using this triplen harmonic compensation method, one can produce the desired output voltage with a converter that has $s-1$ DC sources instead of $s$ DC sources. Similarly, if the switching angles satisfy the condition

$$
\frac{2 \pi}{3}-\theta_{s-1} \leq \theta_{s-3},
$$

then by using this triplen harmonic compensation method, a multilevel converter with $s-2$ DC sources can eliminate the same number of harmonics as a multilevel converter with $s$ DC sources and no triplen harmonic injection.

Repeating this process, one can find all the possible compensations with the fundamental frequency switching angles. For convenience, here the normalized modulation index is defined as $m_{a}=\pi V_{l} /\left(4 V_{d c}\right) / s$. A comparison of the normalized modulation index range with and without the triplen harmonics compensation is shown in Table I for the case of $s=10$ (21-level converter).

Table I. Comparison of the modulation index range with and without triplen harmonic compensation for 21-level converter $(s=10)$

\begin{tabular}{|c|c|c|}
\hline Level Number & $m_{a n c}{ }^{*}$ & $m_{a c} * *$ \\
\hline 5 & $0 \sim 0.19$ & $0 \sim 0.19$ \\
\hline 7 & $0 \sim 0.25$ & $0 \sim 0.276$ \\
\hline 9 & $0 \sim 0.342$ & $0 \sim 0.366$ \\
\hline 11 & $0 \sim 0.423$ & $0 \sim 0.456$ \\
\hline 13 & $0 \sim 0.513$ & $0 \sim 0.542$ \\
\hline 15 & $0 \sim 0.542$ & $0 \sim 0.601$ \\
\hline 17 & $0 \sim 0.601$ & $0 \sim 0.660$ \\
\hline 19 & $0 \sim 0.620$ & $\mathrm{~N} / \mathrm{A}$ \\
\hline \multirow{2}{*}{21} & $0 \sim 0.660$ & $\mathrm{~N} / \mathrm{A}$ \\
\hline$m_{a n c \mid}:$ & $\begin{array}{l}\text { Modulation index range without triplen harmonic } \\
\text { compensation. } \\
* * m_{a c}:\end{array}$ \\
& $\begin{array}{l}\text { Modulation index range with triplen harmonic } \\
\text { compensation. }\end{array}$
\end{tabular}




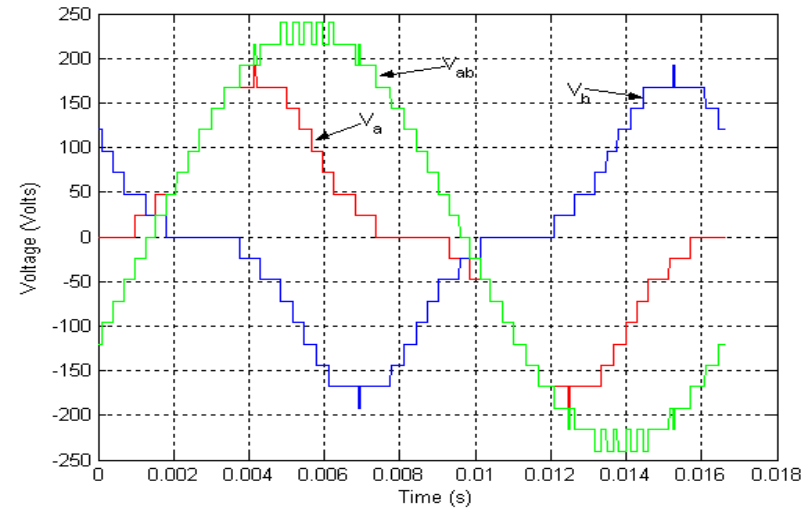

Fig. 5. Phase voltage and line-line voltage simulation of a 17-level multilevel converter without triplen harmonic compensation $\left(m_{a}=0.395\right)$.

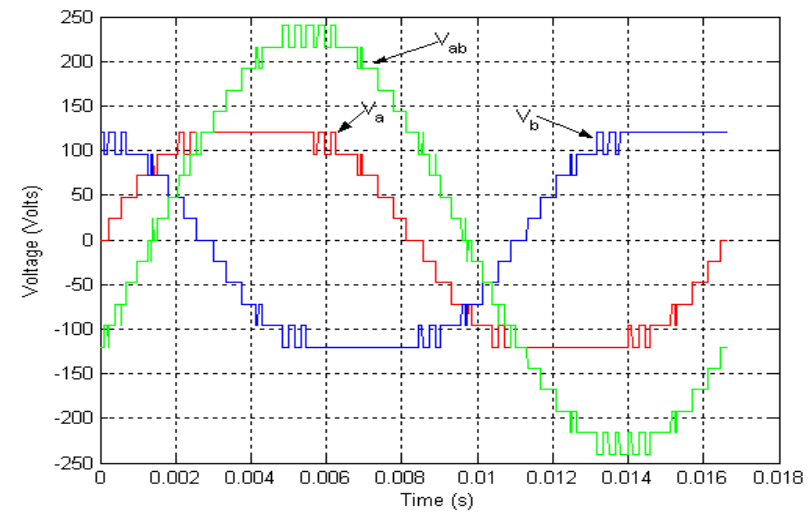

Fig. 6. Phase voltage and line-line voltage simulation of a 17-level multilevel converter with triplen harmonic compensation $\left(m_{a}=0.395\right)$.

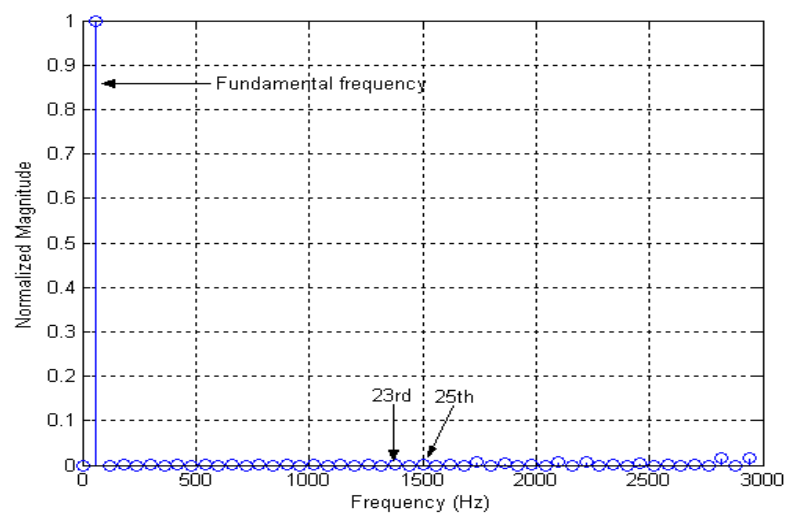

Fig. 7. Normalized FFT analysis of the line-line voltage shown in Fig. 5 and Fig. 6.

The triplen harmonic compensation method increases the modulation index range. For example, without the triplen harmonic compensation, a modulation index $m_{a}=0.660$ realization requires a $21-$ level converter, but with the triplen harmonic compensation method, such a modulation realization only needs a 17-level converter. This can decrease the hardware cost.

To confirm the switching angle computation for the fundamental frequency switching scheme and the triplen harmonic compensation method, a 17-level case with $m_{a}=0.395$ is simulated. The output phase voltage without triplen harmonic compensation requires 17 levels; the phase voltage with triplen harmonic compensation requires 11 levels. The output line-line voltages, which have no harmonics below the 23rd, are the same with and without triplen harmonic compensation.

The simulated voltage waveforms with and without triplen harmonic compensation are shown in Figs. 5 and 6, separately. From the simulation figures, it can be derived that the phase voltage without triplen harmonic compensation has 17 levels, and the phase voltage with triplen harmonic compensation has just 11 levels. The two phase voltages generate the same lineline voltages. The normalized FFT analysis of the line-line voltage shown in Fig. 7 has no harmonics below the 23rd. The simulation results confirm the switching angle computation and modulation extension with the triplen harmonic compensation method.

\section{EXPERIMENTAL IMPLEMENTATION}

To experimentally validate the modulation extension control method, a 17-level case with triplen harmonic compensation is implemented on an 11-level H-bridge multilevel converter.

The prototype three-phase 11-level cascaded H-bridge multilevel converter was built at Oak Ridge National Laboratory using $60 \mathrm{~V}, 70$ A MOSFETs as the switching devices and is shown in Fig. 8. A battery bank of 15 separate DC sources (SDCSs) of $24 \mathrm{~V} \mathrm{DC}$ each feed the converter (five SDCSs per phase). A real-time controller based on an Altera FLEX 10K field programmable gate array (FPGA) is used to implement the algorithm with $8 \mu$ s control resolution.

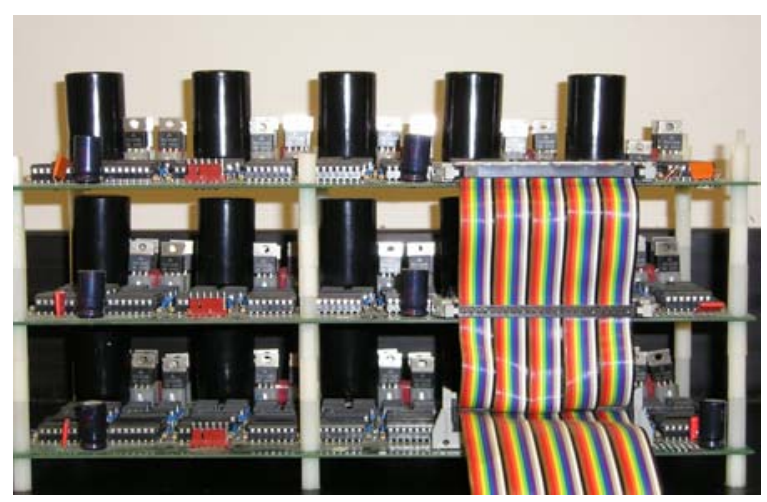

Fig. 8. $10 \mathrm{~kW}$ multilevel converter prototype.

The experimental phase voltage shown in Fig. 9 confirms that a 17-level voltage case can be implemented using an 11level multilevel converter with the triplen harmonic compensation method.

The line-line voltage generated by the 11-level multilevel converter with the triplen harmonic compensation method is shown in Fig. 10, and its normalized FFT analysis given in Fig. 11 shows that all the harmonics below the 23rd are zero. Therefore, the experiments confirm the switching angle computation using the triplen harmonic compensation method combined with the Newton Climbing method. 


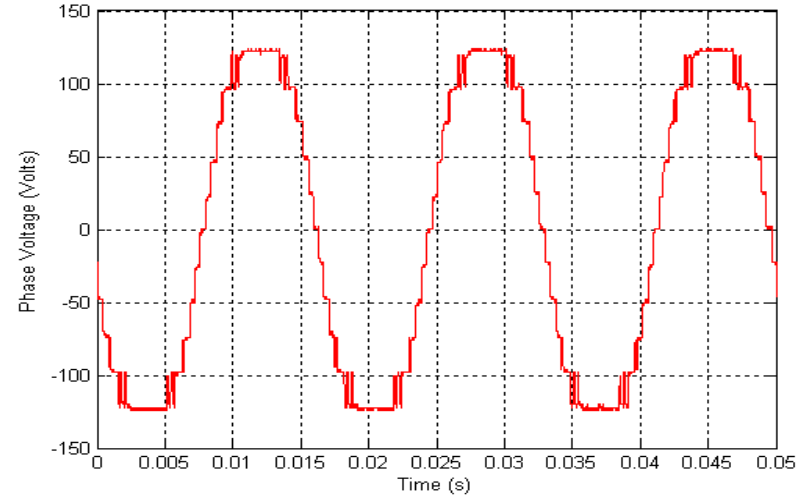

Fig. 9. Experimental phase voltage of a 17-level output using triplen harmonic compensation with only an 11-level converter $\left(m_{a}=0.395\right)$.

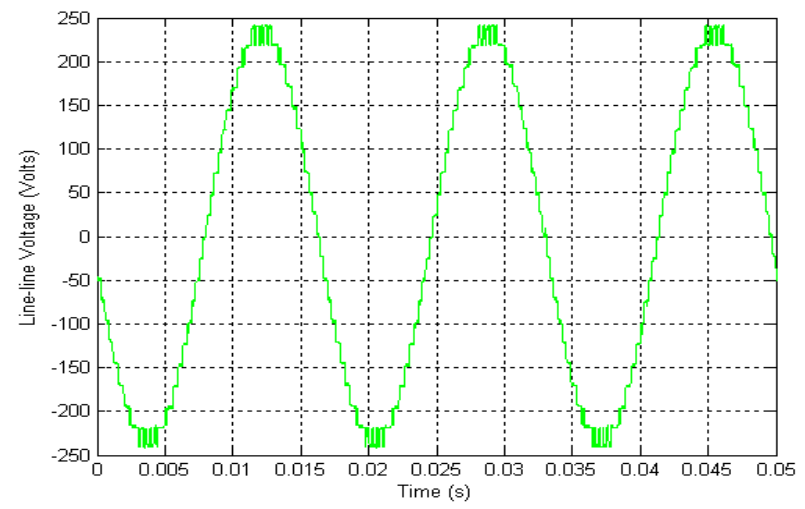

Fig. 10. Experimental line-line voltage of a 17-level multilevel converter $\left(m_{a}=0.395\right)$.

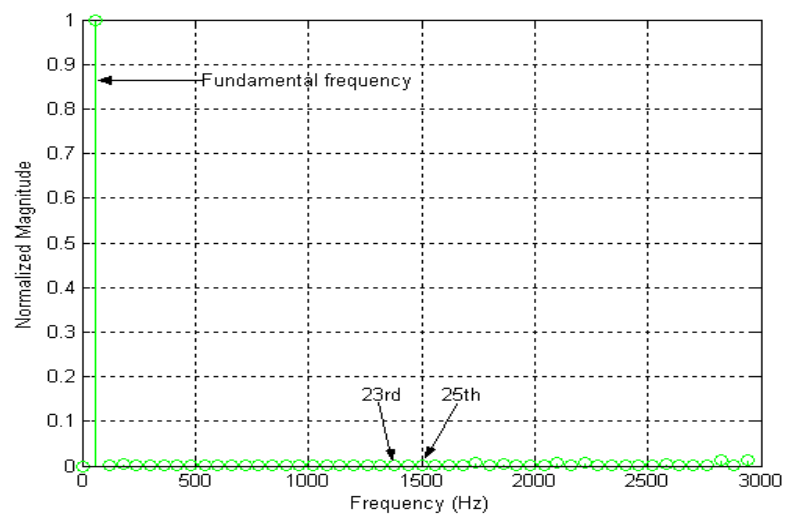

Fig. 11. Normalized FFT analysis of the line-line voltage shown in Fig. 10.

\section{CONCLUSIONS}

The fundamental frequency switching angles for multilevel converters have been computed by the resultant method and the Newton Climbing method. The triplen harmonic compensation method has been proposed to extend the modulation index range for the fundamental frequency switching control. The simulation and experiment validated that the fundamental frequency switching method can eliminate the harmonics as expected, and with the triplen harmonic compensation method, it has wider modulation index range than that of the fundamental frequency switching method.

\section{ACKNOWLEDGMENTS}

We would like to thank the National Science Foundation for partially supporting this work through contract NSF ECS0093884. We would also like to thank Oak Ridge National Laboratory for partially supporting this work through UT/Battelle Contract No. 400023754.

\section{REFERENCES}

[1] H. S. Patel and R. G. Hoft, "Generalized harmonic elimination and voltage control in thyristor inverters: Part I -harmonic elimination," IEEE Trans. Industry Applications, vol. 9, May/June 1973, pp. 310-317.

[2] H. S. Patel and R. G. Hoft, "Generalized harmonic elimination and voltage control in thyristor inverters: Part II -voltage control technique," IEEE Trans. Ind. Applications, vol. 10, Sept./Oct. 1974, pp. 666-673.

[3] J. K. Steinke, "Control strategy for a three phase AC traction drive with a 3-level GTO PWM inverter," IEEE PESC, 1988, pp. 431-438.

[4] P. N. Enjeti, P. D. Ziogas, J. F. Lindsay, "Programmed PWM techniques to eliminate harmonics: A critical evaluation," IEEE Trans. Industry Applications, vol. 26, no. 2, March/April, 1990. pp. $302-316$.

[5] C. K. Duffey, R. P. Stratford, "Update of harmonic standard IEEE-519: IEEE recommended practices and requirements for harmonic control in electric power systems," IEEE Trans. Industry Applications, vol. 25, no. 6, Nov./Dec. 1989, pp. 1025-1034.

[6] L. M. Tolbert, F. Z. Peng, T. G. Habetler, "Multilevel converters for large electric drives," IEEE Trans. Industry Applications, vol. 35, no. 1, Jan./Feb. 1999, pp. 36-44.

[7] J. N. Chiasson, L. M. Tolbert, K. J. McKenzie, Z. Du, "Control of a multilevel converter using resultant theory," IEEE Trans. Control System Technology, vol. 11, no. 3, May 2003, pp. 345-354.

[8] J. N. Chiasson, L. M. Tolbert, K. J. McKenzie, Z. Du, "A unified approach to solving the harmonic elimination equations in multilevel converters," IEEE Trans. Power Electronics, vol. 19, no. 2, March 2004, pp. 478-490.

[9] P. Hammond, "A new approach to enhance power quality for medium voltage ac drives," IEEE Trans. Industry Applications, vol. 33, Jan./Feb. 1997, pp. 202-208.

[10] W. A. Hill and C. D. Harbourt, "Performance of medium voltage multilevel inverters," IEEE Industry Applications Society Annual Meeting, October 1999, Phoenix, AZ, pp. 1186-1192.

[11] G. Carrara, S. Gardella, M. Marchesoni, R. Salutari, G. Sciutto, "A new multilevel PWM method: A theoretical analysis," IEEE Trans. Power Electronics, vol. 7, no. 3, July 1992, pp. 497-505.

[12] L. M. Tolbert, F. Z. Peng, T. G. Habetler, "Multilevel PWM methods at low modulation indices," IEEE Trans. Power Electronics, vol. 15, no. 4, July 2000, pp. 719-725.

[13] L. M. Tolbert, T. G. Habetler, "Novel multilevel inverter carrier-based PWM method," IEEE Trans. Industry Applications, vol. 35, no. 5, Sept./Oct. 1999, pp. 1098-1107.

[14] D. G. Holmes, "The significance of zero space vector placement for carrier based PWM schemes," IEEE IAS Annual Meeting, 1995, pp. 2451-2458.

[15] J. Vassallo, J. C. Clare, P. W. Wheeler, "A power-equalized harmonicelimination scheme for utility-connected cascaded H-bridge multilevel converters," IEEE Industrial Electronics Society Annual Conference, 2-6 Nov. 2003, pp. 1185-1190.

[16] S. Sirisukprasert, J.-S. Lai, T.-H. Liu, "Optimum harmonic reduction with a wide range of modulation indexes for multilevel converters," IEEE Trans. Ind. Electronics, vol. 49, no. 4, Aug. 2002, pp. 875-881.

[17] T. Kato, "Sequential homotopy-based computation of multiple solutions for selected harmonic elimination in PWM inverters," IEEE Trans. Circuits and Systems I, vol. 46, no. 5, May 1999, pp. 586-593. 